\title{
CHARACTERISTICS OF THE ARCHIVAL FOND OF „KONVENTO POLONIA AKTAI” FROM THE WRÓBLEWSKI LIBRARY OF THE LITHUANIAN ACADEMY OF SCIENCES
}

Konwent Polonia was founded in 1828 in Dorpat (modern Tartu in Estonia) and operates till this day as the oldest Polish academic fraternity. Its history in years 1828-1918 was rather tumultuous due to the state of the fraternity in the period of Partitions ${ }^{1}$. In turn, during the Interwar period the fraternity movement flourished and academic fraternities became one of the most pivotal student organizations of the Second Republic of Poland. Konwent Polonia relocated to Vilnius where it functioned until the outbreak of the World War II.

The following paper is the continuation of research concerning the achievements of fraternity movements in Poland which survived until modern times in insubstantial amounts. The archive of Konwent Polonia constitutes the largest surviving collection of documentation concerning the activities of a singular fraternity. Until now the topics relating to the archives of Konwent collected in the Archdiocesan Archive in Warsaw ${ }^{2}$ and General Sikorski Polish Institute and Museum in London ${ }^{3}$ have been compiled and covered. The third most significant collection of documents relating to this particular fraternity is the archival fond kept in the Wróblewski Library of the Lithuanian Academy of Sciences.

It was here where during the World War II the majority of Dorpat and Vilnius documents relating to Konwent Polonia was secured and preserved. Initially it was handed over as a deposit to be retrieved by the new authorities of Konwent after conclusion of war. As future events proved it was no longer possible and the collection was taken over by Lithuanian state. Over the years the institution keeping the discussed collection went through several restructurings related with e.g. political situation. Currently it operates under the name of Wróblewski Library of the Lithuanian Academy of Sciences and is located in Vilnius at Žygimantų g. 1 address.

* Translated by Spektra Sp. z o.o.

1 The history of Konwent Polonia in years 1828-1918 is described in, for instance, works of: Arkadiusz Janicki: A. Janicki, M. Laszczkowski, Polskie korporacje battyckie przed 1918 rokiem, Warszawa 2011, pp. 42-63.

2 "Zespół archiwalny Konwent Polonia jako źródło archiwalne” [ $t$ - Archival fond Konwent Polonia as an archival resource] paper was prepared for printing.

3 „Zespół Korporacja Akademicka Konwent Polonia w Instytucie Polskim i Muzeum im. gen. Sikorskiego - uwagi" [tn - Konwent Polonia fraternity in Polish Institute and General Sikorski Museum - annotations] was prepared for printing and will be published in „Teki archiwalne” magazine. 
The fond was compiled in 1954 and initially assigned signature $\mathrm{KPA}^{4}$. [consecutive number]. Currently it can be found under signature F.160-[consecutive number $]^{5}$. At the time of compiling all filing system aides were prepared in Russian language and since then probably have not been supplemented or updated. A card inventory recorded mostly in Russian language created at that time is the sole record keeping aide available for the discussed archival fond. A certain inconsistency occurred during the creation of the card inventory as the language used during the creation of inventory cards was not unified. Therefore titles in Russian language only were listed on inventory cards of the following units: 1-69, 71-72, 74-76, 78-79, 84, 86-94, 96, 111-112, 114-126, 138, 146, 192, 195-196, 199-204, 206-207,209$-213,215,218,220-225,227-228,230-233,250,253-254,267,287,290-291,294,297-312$, 323, 327, 332, 360-362, 365-369, 371-374, 376, 380, 385, 389, 393-397, 400; titles in Polish language on cards no.: 70, 108 -110, 149-150, 152 -158, 160-163, 165-168, 171-172, 174-176, 178, 180-185, 188-191, 205, 208, 214, 216-217, 219, 226, 235-239, 248, 251-252, 255-257, 259-266, 268-286, 288-289, 296, 314 -318, 320, 324-326, 328-331, 384, 386 -388, 391, 399; bilingual Polish-Russian titles were listed on cards no.: 73, 77, 80-83, 85, 95, 97-107,113, $127-137,139,141-145,147-148,151,159,164,169-170,173,177,179,186-187,193$-194, $197-$ $-198,229,234,240-247,249,258,292-293,295,313,319,322,363-364,377,398$. Few files have titles or a fragment of a title in German language: 333, 336, 340-342, 345-357, 370, $375,378-379,381,383,390$, or are bilingual, German-Russian: 321, 334-335, 337-339, 343-344, 358-359, 382, 392, or German-Lithuanian: 402-404. The last type is Polish-LithuaniaRussian: 140 or Polish-Lithuanian titles: 401. The different language of the units would be completely understandable if it reflected contents of the units; however, in this case we are dealing with situation in which the original names of a part of units were retained whereas names were changed for others ${ }^{6}$.

The later corrections in the compiled fond (end of the 20th and beginning of the 21st century) were mostly concerned with completing missing or correcting incorrect foliation ${ }^{7}$. This is evidenced by the annotations included in the certificate of the archival unit. Technical mistakes of this kind were probably uncovered when the fond was made accessible to users ${ }^{8}$. It should be noted that the incorrect physical numbering was not removed but the correct foliation was marked beside the old foliation which was crossed out ${ }^{9}$. When foliation was not printed on a card the entirety of numbering was not corrected but additional reference signatures, beginning with the consecutive letters of the Latin alphabet, were added. It is conceivable that also these corrections were made when the fond was made available to users. Of course it leads to a situation when the information included in the imprint become obsolete. However, this problem was solved by providing appropriate information in the pastabos (notes) column.

\footnotetext{
4 KPA - Konvento Polonia aktai.

5 In this case the letter $\mathrm{F}$ in signature denotes ,fonds d' archive” (Fr.)

6 The archive inventory in BLAN has the form of card inventory and is not publicly available in the Internet. Therefore the author decided to not make it public.

7 Archival fond was at least partially repackaged. Some of the units are being stored in dustcovers which simultaneously serve as imprints for individual archival units. Additionally certain unites were stitched and bound.

8 We may formulate such thesis by comparing the dates when corrections were made with the dates when photocopies o individual units were made.

9 It applies to, for instance, unit F.160-16.
} 
In regard to compilation process it must be noted that during the process of compiling of the fond no single method was developed. It concerns both the degree of selection of the archive materials as well as creation of the archival units and internal arrangement of the units. An excellent example of this is an extensive collection of correspondence arranged in to the following units: F.160-5 - F.160-69, F.160-71 - F.160.72, F.160-74, F.160-78 - F.160-82, F.160-86-F. 160-94, F.160-205, which also includes correspondence logs registered under signatures F.160-210- F.160-213. Unfortunately it was not arranged in any coherent manner as evidenced by a rather chaotic spreading of the collection across the entire fond. Relative chaos in files and the experience acquired during work with the Konwent documentation gathered in AAW [tn - Archiwum Archidiecezji Warszawskiej - Archdiocesan Archive in Warsaw] suggests that when the collection was being secured during the World War II the materials handed over to BLAN [tn -Biblioteka Litewskiej Akademin Nauk - Lithuanian Academy of Sciences Library] could have become shuffled. Unfortunately, during the archival works no adequate effort was made to organize and properly arrange the documentation. It is evidenced by the lack of clues which would allow us to ascertain what filing and compiling method the archivist used. Using the current arrangement of units we are unable to ascertain or identify the structure of cells operating within Konwent fraternity nor are we able to uncover traces of creation of thematic groups.

Apart from the issue of establishing individual archival units certain units lack internal consistency which could be achieved by, for instance, arranging material in chronological order which currently is, in case of some of the units, disturbed ${ }^{10}$. It appears that the individual working on the fond did not adopt any rules concerning the chronological arrangement of files - whether it should be ascending or descending. It is suggested by the occurrence of both of these types of arrangement.

The archival fond consists of 404 inventory units in total and additionally some of them could be further divided into several separate archival units ${ }^{11}$. Unfortunately the reasons as to why archival units do not correlate with inventory units are uncertain. It appears that it could have resulted from the need to separate documentation concerning different subjects or from the significant size of a given unit ${ }^{12}$. However, in this case none of the mentioned circumstances occur.

Two criteria will be used to describe this documentation: chronological and substantive. In case of the former it will be able to distinguish the period: Dorpat or Vilnius, the latter will enable us to present the diversity of the collected archival materials. It will enable us to ascertain the degree to which the AAW and BLAN fraternity archives are convergent and to what degree they supplement each other.

The documents created till 1918, the conclusion of First World War and the return of Poland to the map of Europe, as well as till the relocation of the fraternity headquarters from

\footnotetext{
10 One such example is F.160-81 unit consisting of duplicates of outgoing documents from years 1928-1930. It contains two duplicates of the letter to count Collon-Czosnowski, both of which were even assigned identical signatures: 263/30. One of the duplicates was hand-written and a second duplicate was made by copying the latter on a typewriter. The latter version can be located on cards $79-80 \mathrm{v}$ and the former on pages 45-46

11 For instance, inventory unit F.160-64 is divided into three archival units: F.160-64/1, F.160-64/2 i F.160-64. The situation is identical in case of, for instance: F.160-65 (3 archival units), F.160-86 (2 a.u.) i F.160-99 (4 a.u.).

12 In case of great diversity of documents it would be prudent to carry out more detailed and precise classifications and form new units.
} 
Dorpat to Vilnius in 1919, can be considered the Dorpat period documentation. It consist of 140 units: F.160-1 - F.160-7, F.160-73, F.160-75, F.160-77, F.160-83, F. 160-84, F.160-96 - F.160-98, F.160-109, F.160-110, F.16-123, F.160-126, F.160-131, F.160-145, F.160-148, F.160-149, F.160-180- F.160-186, F.160-189- F.160-192, F.160-194, F.160-198, F.160-214, F.160-216, F.160-235-F.160-247, F.160-250, F.160-255-F.160-257, F.160-313 - F.160-324, F.160-326, F.160-327, F.160-330-F.160-360, F.160-362, F.160-365-F.160-376, F.160-378F.160-396, F.160-402 - F.160-404. There are only 18 units containing documentation from both periods: F.160-13, F.160-71, F.160-124, F.160-127, F.160-133, F.160-143, F.160-197, F.160-200 - F.160-202, F.160-208, F.160-221, F.160-226, F.160-234, F.160-248, F.160-249, F.160-312, F.160-400. In case of three units we were unable to establish the time-frame: F.160-193, F.160-195, F.160-199. The remaining 243 units come from the Vilnius period. Therefore, the Dorpat period documentation covers more than $33 \%$ of the inventory units ${ }^{13}$, a fact which is not reflected in any form by the structure of the fond.

The substantive criterion allows us to study the collection in greater detail. We are able to distinguish between dozen or so main thematic groups:

- $\quad$ Secretarial files (F.160-1 - F.160-4, F.160-83, F.160-131)

- Inward correspondence: (F.160-5 - F.160-69, F.160-71, F.160-72, F.160-78, F.16079, F.160-86, F.160-87, F.160-89, F.160-90, F.160-397), outgoing correspondence (F.160-74, F.160-80 - F.160-82, F.160-88, F.160-91 - F.160-94), correspondence logs (F.160-210 - F.160-213)

- Court records: Permanent Court of Honor (F.160-95, F.160-99, F.160-100 - F.160107, F.160-109, F.160-140), Permanent Fraternity Court (F.160-124, F.160-218)

- Minutes and reports (F.160-110, F.160-111, F.160-123, F.160-125, F.160-126, F.160138, F.160-144, F.160-145)

- Normative files: charters, rules and regulations (F.160-130, F.160-132, F.160-134- F.160-137)

- Materials concerning activities under Polish Academic Fraternities Association (PAFA) (F.160-108, F.160-112, F.160-113-F.160- 122, F.160-128, F.160-134, F.160139, F.160-142)

- Materials concerning celebrations of centennial anniversary of the fraternity (F.16076, F.160-204- F.160-207, F.160-217)

- $\quad$ Financial records (F.160-73, F.160-96- F.160-98, F.160-127, F.160-143, F.160-202, F.160-208, F.160-209, F.160-226, F.160-234, F.160-312- F.160-322, F.160-324F.160-330, F.160-384 - F.160-387, F.160-391 - F.160-396, F.160-399-F.160-400)

- $\quad$ Library records (F.160-214, F.160-235- F.160-252, F.160-254 - F.160-257)

- List of members (F.160-215, F.160-216, F.160-219-F.160-223, F.160-227-F.160-233)

- Documentation and records of individuals not admitted into fraternity and former members (F.160-224, F.160-225, F.160-331)

- Books of attendance (F.160-258 - F.160-311)

- Coloriariis and fraternity candidates files (F.160-146- F.160-199)

- $\quad$ Lecture notes (F.160-332 - F.160-360, F.160-362 - F.160-383, F.160-401 - F.160-404)

\footnotetext{
13 The presented 33\% does not include units containing documentation from both periods and three units with unspecified chronology.
} 
- Other (F.160-70, F.160-75, F.160-77, F.160-84, F.160-85, F.160-129, F.160-133, F.160- 141, F.160-200, F.160-201, F.160-253, F.160-323, F.160-361, F.160-388 F.160-390, F.160-398, F.160-401 - F.160-404).

The first listed thematic group - „secretarial files" - consists of 6 archival units chronologically covering years $1895-1910$ and 1912-1917. Therefore it constitutes a supplement for the documentation of the same type collected in AAW (year 1883-1898). They have a form of a notebook (F.160-1, F.160-83, F.160-131) as well as individual cards and pages. Similarly to the documentation stored in Warsaw these files consist mainly of correspondence and related attachments.

The second thematic group, collection of correspondence, supplements the secretarial files from the Dorpat period. However, unlike in the above example, it was not collected and bound in the form of a notebook. In the Dorpat period only three units containing inward correspondence from the 1909-1917 period were distinguished (F.160-5 - F.160-7) and two units containing material from both discussed periods from the years 1917-1939 (F.160-13, F.160-71). What is interesting and characteristic in the Vilnius period secretarial files no longer constituted a separate group and were incorporated into correspondence collection. It could have been the result of the significant increase in the amount of incoming documents related with the development of fraternity movements and foundation of numerous new fraternities as well as other institutions with which contact was maintained. Probably the same circumstances influenced and contributed to the use of correspondence logs in order to organize a significant number of documents going through the administrative office of the Konwent.

The collected correspondence is varied and diverse. It contains official documents sent by the PAFA (Polish Academic Fraternities Association), local inter-fraternity associations, other fraternities (bound by a pact of friendship and others), university authorities and other government offices, military units and private institutions - Alumnae organizations and Polonus (active and Alumnae). The contents of correspondence are also of particular interest for a researcher because they enable us to procure information concerning the composition of presidium of other fraternities ${ }^{14}$, relations between Konwent and other fraternities and Konwent's attitude towards PAFA. It is possible owing to Konwent Polonia being a member of inter-fraternity structures and Konwent maintaining relations with numerous fraternities, particularly from the area of Vilnius. The analysis of the activities of „Wiadomości Korporacyjne” [tn - Fraternity News] editorial office, which sent rather large amount of various messages, urgings and settlements, is also possible.

The majority of correspondence consists of various invitations, mostly to balls organized by other fraternities, military units or industry associations ${ }^{15}$, but also invitations to weddings,

\footnotetext{
14 Sending information concerning the composition of the newly elected presidium to other fraternities with which contact was maintained was a common custom. Because of this members of the fraternity regularly received information concerning new authorities from several dozen other fraternities. Konwent Polonia also forwarded this type of information to a significant number of fraternities; BLAN, F.160-210-F.160-213.

15 Konwent was invited by, for instance: Wileńskie Koło Młodych Ziemianek [tn - Villnius Young Female Landowners Association] (for ,a black coffee” on the 13th of February 1927), Commandant, Officers and Cadets from Grudziąc Cavalry School (for the Cadet Ball on the 8th of February 1927), USB Russian Students Association (for the Annual Concert-Ball on the 16th of February 1928) or the division of Villnius Association of State Officials on the 1st of March 1924); BLAN:F.160-52, k.27, F.160-16, k.80, F.160-42, k.50, F.160-11, k.60.
} 
debates and others. Apart from traditional letters a rather large number of telegrams can be found in the fond ${ }^{16}$.

The outgoing correspondence (F.160-74, F.160-80- F.160- 82, F.160-88, F.160-91F.160-94) and correspondence logs (F.160-210- F.160-213) supplementing the information concerning relations with other institutions, mainly other fraternities, constitute a separate topic.

The next thematic section can be composed of the court records consisting of the documents produced by Permanent Court of Honor (F.160-95, F.160-99, F.160-100 - F.160107, F.160-109, F.160-140) and Permanent Fraternity Court (F.160-124, F.160-218). In the case of Court of Honor the majority of documentation consists of various bills (F.160-95, F.160-99, F.160-140). Chronologically these documents cover periods between 1897-1918 and 1923-1934, whereas the cases described in the documents are mainly related to the financial operations of Konwent, including the fraternity acting as an audit committee. In case of Fraternity Court both of the units consist of documents from the 1916-1934 period.

The other noteworthy sources are minutes and reports (F.160-110, F.160-111, F.160-123, F.160-125, F.160-126, F.160-138, F.160-144, F.160-145). The first unit worthy of discussion is the book of ordinances, resolutions, rules and protocols from the Dorpat period (F.160-110) containing material from years 1897-1918. It includes, for instance, list of the officials of the fraternity. However, it is not the sole unit containing materials from the Dorpat period. One particularly interesting document is the notebook recorded entirely in Russian containing minutes of the fraternity sittings from years 1913-1917 ${ }^{17}$. As Jan Trynkowski suspects it could have been used to present reports on Konwent activities to the university authorities. Closer to the truth are Polish-language minutes from the 1914-1917 period contained in the F.160-145 unit. They could be supplemented with the notebook registered under F.160-126 signature containing minutes from year 1918. However, it must be stressed that this notebook is not uniform in terms of content because it also includes correspondence from 1918. Minutes and reports from the Vilnius period are contained in units F.160-111, F.160-125, F.160-138, F.160-144 and cover the period of 1921-1939 (minutes) and 1921-1937 (reports). Similarly to the correspondence individual documents in certain units were not organized chronologically before being bound (e.g. F.160-111).

The normative files in the following units include charters of Konwent Polonia dated on 1925 (F.160-135) and Welecja fraternity (F.160-132) as well as three charters of PAFA dated on the 15th of June 1922, the 4th of May 1931 and the 20th of January 1932 (F.160-134), a draft of the charter of National Association of Polish Academic Youth (F.160-137) and the rules and regulations of the Inter-Fraternity Association of Vilnius (F.160-136). The last unit (F.160-130) consists of numerous charters and rulebooks.

The materials related to PAFA are also rather plentiful. They consists of minutes of PAFA meetings: II PAFA meeting on the 4th of May 1922 (F.160-122), III PAFA meeting on the

\footnotetext{
16 A historian conducting his research on the basis of correspondence must exercise a great deal of patience. As noted previously, correspondence is not sorted by contents and the chronological division is also of questionable quality. For instance, the correspondence from the year 1923 is collected in 5 units (F.160-8 - F.160-10, F.160-13, F.160-16) and correspondence from the year 1927 in 16 units.(F.160-17-F.160-20, F.160-23, F.160-27, F.160-42, F.160-46-F.160-53, F.160-397).

17 In the case of the mentioned version of records the names of the members of Konwent Polonia are also written in Russian language.
} 
7-10th of May 1923 (F.160-117), IV PAFA meeting on the 8-12th of May 1924 (F.160-118), V PAFA meeting on the 7-11th of May 1925 (F.160-119), VI Extraordinary PAFA meeting on the 20-22nd of November 1925 (F.160-120), VII PAFA meeting on held between 28th of January and the 1st of February 1927 (F.160-121), VIII PAFA meeting on the 7-9th of December 1928 (F.160-114), IX PAFA meeting on the 6-8th December 1930 (F.160-108), X PAFA meeting on the 8-10th of December 1932 (F.160-112), as well as the minutes of the PAFA General Council meetings: I PAFA General Council meeting on the 5-6th of June 1927 (F.160-116), III PAFA General Council meeting on the 7th of December 1928 (F.160-114) ${ }^{18}$, V PAFA General Council meeting in 1930 (F.160-115), VI PAFA General Council meeting on the 21-22nd of November 1931 (F.160-121) ${ }^{19}$. Additionally the PAFA minutes and reports from the period of 1928-1930 (F.160-128) and minutes of the fraternity representatives' conference held in 1926 were collected. (F.160-113) as well as numerous PAFA circular letters from the period of 1922-1933 (F.160-142) ${ }^{20}$. The entirety paints a certain picture of the PAFA's functioning and evolution of this organization.

Any financial statements are particularly interesting in learning about Konwent activities. One characteristic trait is the fact that the majority of financial statements represents the Dorpat period which results from the fact that during the Vilnius period the majority of bills and receipts were incorporated into the documentation of Court of Honor which also functioned as an audit committee. The significant part of the collected materials consists of the registers related with cookhouse/cafeteria operated by the Konwent. On one hand these are the records of debts but on the other these are the list of cookhouse expenses related with the prepared meals and covering period of 1886-1930 (F.160-96, F.160-98, F.160-99, F.160-208, F.160-226, F.160-312, F.160-325, F.160-329, F.160-330). The bills relating to the organization of general meals in years 1913-1918 (F.160-319) and receptions in years 19161917 (F.160-324) also, to a certain degree, constitute the supplement of the cafeteria records. Also the expenditure fund documentation covering years 1884-1924 is rather extensive (F.160-234, F.160-313- F.160-318, F.160-326). Two units cover the issue of scholarship in years 1893-1902 (F.160-320, F.160-386) and further three units contain accommodation records from years 1906-1907 and 1911-1917 (F.160-327, F.160-393, F.160-394). The rather peculiar records are also available, such as: the book of voluntary contributions covering the period of 1881-1928 (F.160-143), records of 1908-1916 representation allowance (F.160384), list of building fund interest rates in years 1912-1915 (F.160-385), Oberfuks fund in 1908-1918 period (F.160-387), and list of Alumnae contributions donated between 1913 and 1917 and in 1921 (F.160-391, F.160-328) ${ }^{21}$, Conto-Buch records (F.160-321, F.160-392), documentation relating to account in Private Commerce Bank in Vilnius in years 1906-1916 (F.160-395) and the list of goods purchased on credit in years 1904-1905 (F.160-396). The rest of the material consist of documentation of a more general nature, such as: Konwent

\footnotetext{
18 Unit F.160-114 contains both the minutes of the VIII meeting of ZPKA (hereinafter PAFA) [tn - Związek Polskich Korporacji Akademickich, PAFA - Polish Academic Fraternities Association] and the III Chief Council of PAFA sitting, both of which took place on the same date.

19 Unit F.160-121 includes both the minutes of the VI rally of the Chief Council of PAFA as well as the minutes of the VII PAFA general meeting .

20 Units F.160-139 and F.160-142 include document concerning the withdrawal of Konwent Polonia from PAFA dated on 1933 and the minutes of I General Meeting of the Chief Council of PAFA on the 5th-6th of June 1927.

${ }^{21}$ One other list of Alumni contributions is located in F.160-312 unit.
} 
reports covering years 1888-1937 (F.160-127), 1917-1918 secretarial bills, 1919-1920 and 1925-1926 cash journals (F.160-209, F.160-299) as well as further bills and receipts from years 1878-1881 and 1893-1927 (F.160-73, F.160-202, F.160-400).

Part of the bills concerns the activities of the library counter in years 1878-1903 (F.160238), 1906-1918 (F.160-255) and 1928-1931 (F.160-251). The archival unit F.160-249 also includes a part of the 1900-1925 financial records in the form of bills for the purchased books $($ F.160-251)22. Furthermore, the documentation produced by the librarian and included in the fond contains the 1922-1923 book loans logs (F.160-254), the 1904-1909 book of subscribers (F.160-256) but most importantly the fond contains numerous library catalogues (F.160-214, F.160-235 - F.160-237, F.160-239-F.160-248, F.160-250, F.160-252, F.160-257). However, it must be stressed that the majority of the catalogues concerns books collected towards the end of the 19th and beginning of the 20th century. Therefore, these catalogues are outdated.

The documentation relating to the celebrations of the 100th anniversary of the fraternity, which was a particularly important event for the member of fraternity, can also be considerate a separate section. It covers the entirety of arrangements and preparations related with organization and progress of the celebrations - beginning with the preserved invitation forms (F.160-206) and the related correspondence concerning the number and composition of delegations as well as the seating arrangement during the celebration (F.160-204). Parts of the outgoing correspondence addressed to Alumni and concerning organization and financial aspects of celebrations were also preserved (F.160-205). On the day of the celebration as well as on the following day numerous congratulatory letters and telegrams were sent, to both other fraternities and Alumni (F.160-207). From the very celebrations a hand-written record of the Alumnus Bohdan Wydżga, consisting of 45k. (F.160-217), survived as well as reports and recollections of the celebrations contained in unit F.160-76 ${ }^{23}$.

The next thematic group is registry of members (F.160-215, F.160-216, F.160- 219 F.160-223, F.160-227 - F.160-233) to various degrees covering years 1916-1938. It lists both the active members and Alumni of the Konwent Polonia. F.160-219 unit, containing surveys and polls filled in by Alumni, is rather special and characteristic. The surveys have form of questionnaires but due to rather significant amount of biographical information they were initially accounted by the author into the thematic group mentioned herein-above. Moreover, this is not the sole surviving registry. The Curriculum Vitae of individuals who were not admitted into Konwent were also preserved (F.160-224) as well as CVs of temporary members (F.160-331) and individuals expelled from the fraternity (F.160-225).

The books of attendance also serve as an excellent source of information concerning members of fraternity. They are a particularly interesting source, even more so due to the fact that they survived only in BLAN. With minor gaps chronologically books cover the period from the March of 1921 till the end of 1938. In certain cases two books of attendance were kept concurrently ${ }^{24}$. Unfortunately the order in which the books were placed in the fond

\footnotetext{
22 Unit F.160-249 also includes work schedule of the librarian.

23 This unit also includes, among other documents, the record of resolutions adopted during consultation meeting between Konwent, Arkonia, Walecja, Sarmatia and Jagiellonia fraternities; F.160-76, k. 13-17.

24 For instance, unit F.160-261 covers the period between 25th of February 1925 and 27th of January 1926. At that time records covering the period between the 11th of November 1924 and the 3rd of May 1925 were simultaneously kept (F. 160-264), from the 3rd of May 1925 till the 1st of October 1925. (F. 160-263), from the 10th of October
} 
appears to be completely coincidental and random. There was a multitude of reasons to create a book of attendance, a fact which was indicated in the introduction to the 1932-1933 book:

Why do we need a book of attendance?

So each of the members present in Konwent could affix his signature therein.

So each interested individual could learn: who was present and what he could have to communicate to others.

So we could ipso facto notify in few words the interested individuals about incidents, needs etc.

So the book could become a record of the life of Konwent.

So the book did not make a bad impression on aesthetically inclined individuals.

To maintain the values: frugality, orderliness and cleanliness.

What are you prohibited from doing?

From scribbling!

From smudging!

From tearing pages.

From writing down nonsense.

All in accordance with old saying: "Clothes make the man".

Remember! Offenders will be held liable before the Konwent Court! ${ }^{25}$

As the members of Konwent indicated the object of the book was to preserve the information about the internal life of Konwent; this objective was achieved. Apart from the information concerning the attendance of meetings in the quarters of Konwent the book includes various other information such as notes and orders from one member to others; because of this it may seem that the book played the role of a notice board of sorts. Apart from that the book was an outlet for artistically inclined Polonus talented in writing and drawing - the book is illustrated with numerous drawings, cartoons and caricatures and contains various short poems or stage plays scripts.

A part of the discussed books F.160-292 - F.160-295, F.160-300 - F.160-302) includes an annotation from the archivist: имеются порнографические рисунки which draws the attention to rather coarse character of certain drawings and pictures.

The next section consists of scientific papers which were preserved in significant amount. They were delivered by members of Konwent (F.160-146 - F.160-199), mainly by members not fully inducted into fraternity, but at times they were delivered by coloriariis. These papers covered various subjects, from the issues pertaining to the history of Konwent (e.g. Witold Kisiel's paper on the 100th anniversary of the fraternity ${ }^{26}$ ) to historical and social topics. All in all, in terms of works of writing created by the members of Konwent, a large number of lecture notes (F.160-332- F.160-360, F.160-362- F.160-383, F.160-401 - F.160-404),

1925 til the 5th of November 1925 (F.160-262). Chronologically the next book covers the period from the 28th of January 1926 til the 15th of May 1926, therefore it is a direct continuation of F.160-261 unit.

25 BLAN, F.160-282, k.1.

26 BLAN, F.160-147. 
mainly written down by a student of Theology, Henryk Tochterman, mostly in German language, was preserved.

The materials not divided into separate thematic groups will be discussed last - not because of their insignificant substantive value but due to the fact that their diversity and uniqueness makes it impossible to classify them and assign them to any of the groups listed herein-above. These materials consist of:

- A Nativity scene prepared by Jan Niedziałkowski on the 21st of March 1936. (F.160-70)

- Polish folk songs written down by Olgierd Tarkiewicz in the Drabiszki domain in Wiłkomierski county (F.160-75)

- Materials related to balls organized by Konwent in years 1911 and 1914 (F.160-77)

- Four 1911 photographs depicting Konwent's quarters at Rathaustrasse and a group of Konwent members (F.160-84)

- $\quad$ Printed matter, including "Korporant [tn - member of fraternity] and "Wiadomości Korporacyjne [tn - fraternity news]" newsletters (F.160-85)

- Materials relating to codification of: Rules and Regulations of Konwent and Konwent Code of Honour (F.160-129)

- Designs and drawings of quarters, furniture, uniforms etc. (F.160-133)

- $\quad$ List of the 1922 moveable assets of Konwent (F.160-141)

- Konrad Niedziałkowski's ${ }^{27}$ personal and familial documentation covering the $1841-$ 1926 period (F.160-200, F.160-201)

- Designs of the fraternity coats-of-arms: Viginita and Karpatia (F.160-253)

- An 1895-1901 index book of a student of University of Jurjew (F.160-323)

- Various short Konwent documents including correspondence (F.160-361)

- A fragment of "Jordan" stage play by Edward Żeligowski (F.160-388)

- A Roman law history tractate (F.160-389)

- Schedule of the First Scientific Congress of the Polish Academic Youth in 1931 (F.160-398).

It should be stressed that the discussed archive fond is exceptionally voluminous and its most valuable element is the plenteous collection of correspondence. In turn, it does not include almost any photographs, merely those contained in F.160-84 unit and singular pictures included with other pieces of documentation. Therefore the researcher will be able to obtain the entirety of information contained within the discussed fond only after familiarizing himself with other collections stored in Warsaw and in London.

Apart from the rather detailed description of the everyday operations of the fraternity and everyday life of its members the value of this fond lies mainly with the fact that it was preserved in a nearly complete state. From the point of view of an archivist we should be grateful to the members of Konwent for remaining and operating in the area of Vilnius despite the plans to move the headquarters of Konwent shortly after conclusion of the First World War. This way the Konwent archives avoided the fate of other Warsaw archives and complete fragmentation of its collection.

27 Konrad Niedziałkowski - father of Jan Niedziałkowski, member of the Konwent. 


\section{Characteristics of the archival fond of „Konvento Polonia aktai” from the Wroblewski Library of the Lithuanian Academy of Sciences Summary}

After World War II documentation of archive of the Konwent Polonia was dispersed. Currently, it is gathered in three institutions: The Archdiocesan Archive of Warsaw, The Wroblewski Library of the Lithuanian Academy of Sciences in Vilnius and The Polish Institute and Sikorski Museum in London. This study presents a Vilnius collection - both structure of the archival fond and the information value of gathered archival units. It is extremely useful for researchers - particularly in the context of the lack of online inventories, as well as factual mistakes committed during the archival description of the records gathered there.

This archival fond consists of 404 units and it is one of the most important sources for the history of both the Konwent Polonia and polish fraternities. Especially that most of fraternities archives were destroyed, and the total number of members of all academic fraternities until the outbreak of World War II was at least over a twelve thousand

Keywords: Konwent Polonia, archive science, academic fraternity, Vilnius, student associations

About the author: dr Karol Dowgialo archivist, expert on the archival science and history of academic fraternities. He is further interested in the middle-ages military history. 